\title{
Severe late failure of a porcine xenograft mitral valve: clinical, echocardiographic, and pathological findings
}

\author{
GIANCARLO CRUPI, DEREK GIBSON, BRIAN HEARD, AND \\ CHRISTOPHER LINCOLN
}

From the Department of Surgery, Cardiothoracic Institute, Brompton Hospital, London

\begin{abstract}
A case of dysfunction of a Carpentier-Edwards porcine xenograft mitral prosthesio is presented. Valve failure was diagnosed by echocardiography and confirmed at operation. Histology showed valve tissue degeneration without evidence of prosthetic endocarditis.
\end{abstract}

Several clinical studies have demonstrated that the porcine aortic xenograft prosthesis fulfils many of the criteria for a satisfactory valve substitute for atrioventricular valve replacement. ${ }^{1-3}$ The durability of this prosthesis has been increased by the use of a flexible stent and glutaraldehyde preservation, and shown to exceed that of previously available tissue valves.

However, several instances of valve failure have been reported even with porcine xenograft prostheses. ${ }^{2-6}$

In this report we describe the clinical, echocardiographic, and pathological findings in an 11-year-old patient in whom dysfunction of a Carpentier-Edwards porcine xenograft mitral valve occurred two and a half years after its implantation. Valve failure was diagnosed by echocardiography and confirmed at operation. This appears to be the first reported case of valve failure of the Carpentier-Edwards xenograft since its clinical use began in 1975.

\section{Case report}

A 9-year-old boy was admitted to Brompton Hospital for investigation of mitral valve disease. Cardiac catheterisation confirmed the presence of severe mitral regurgitation. At operation he was found to have a parachute mitral valve with very abnormal leaflets. Satisfactory repair was not thought to be feasible and so the valve was excised and replaced with a $29 \mathrm{~mm}$ CarpentierEdwards porcine xenograft prosthesis. After operation, the patient's clinical state was greatly improved, and it was possible to discontinue

Address for reprint requests: Christopher Lincoln, Brompton Hospital, Fulham Road, London SW3 6HP.

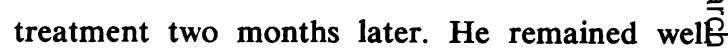
for two and a half years and then suddenly be $\overrightarrow{c 0}$ came severely breathless when walking. He waso admitted to hospital and found to be in severe left ventricular failure which responded initially to digoxin and diuretics. He was transferred tos Brompton Hospital where he was found to have evidence of pulmonary oedema, and to have कo soft systolic murmur at the apex. The pulmonarye component of the second heart sound was ac $\overrightarrow{\overrightarrow{0}}$ centuated. A chest radiograph showed a norma $\bar{B}$ sized heart with dilatation of the upper lobe veins. Echocardiography showed a transverse lefe. ventricular dimension of $5.0 \mathrm{~cm}$ at end-diastole Peak diastolic rate of dimension increase was? $25 \mathrm{~cm} / \mathrm{s}$. The pattern of movement of the cusps of the prosthesis was abnormal. There was an amor윽 phous group of echoes within the valve ring during diastole which disappeared during systole The diagnosis was severe mitral regurgitation through rather than around the prosthesis as sociated with disorganisation of the cusps. A reoperation one of the cusps of the xenografte. showed heavy calcification and another was torrif off at its commissural attachment. The prosthesis was excised and replaced with a 2M 6120 Starr: Edwards valve. The postoperative course wasi uneventful.

\section{PATHOLOGY}

The valve cusps were rigid, the orifice admitting only the tip of the finger with difficulty. Theid general shape was preserved, but they were्ह diffusely thickened and opaque as a result of patches of calcification. There was a hole $2 \mathrm{~mm}^{2}$ in diameter near the centre of one of the cuspse and part of this cusp was detached from the्巳 


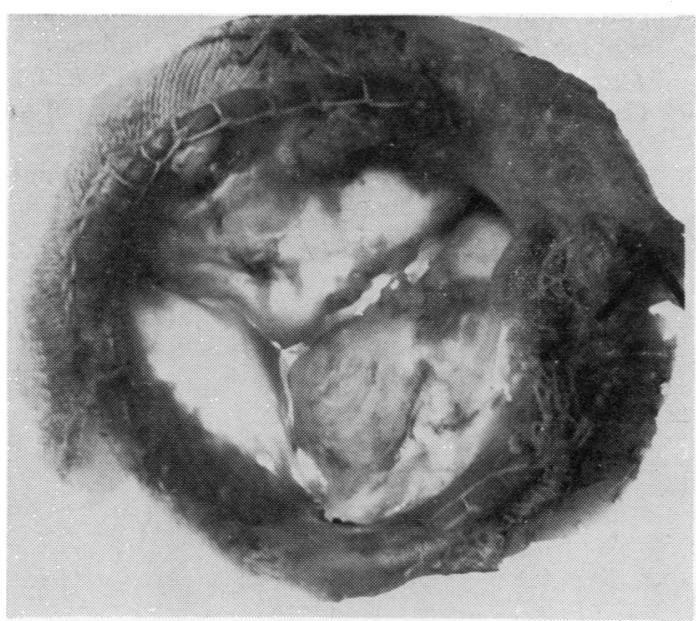

(a)

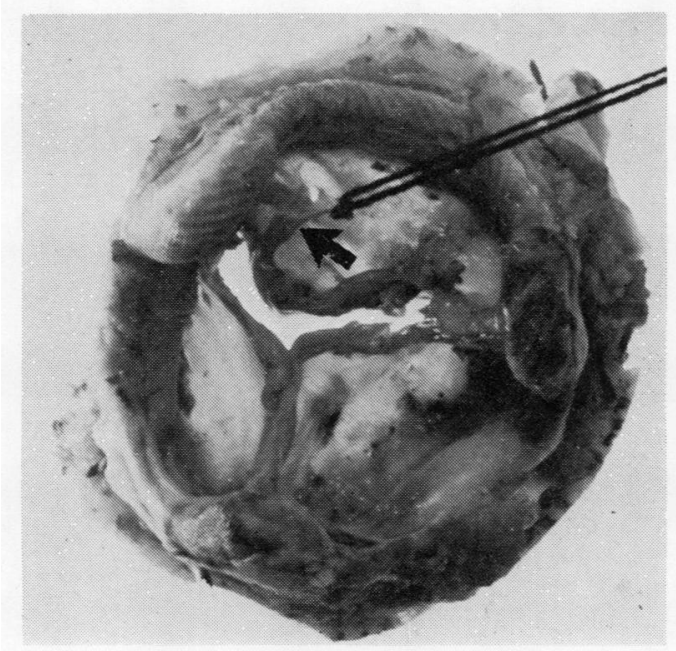

(b)

Fig Atrial (a) and ventricular (b) views of a porcine xenograft mitral prosthesis removed two and a half years after its insertion. Heavy calcification is present in two leaflets. The superior leaflet is detached from the prosthetic annulus at one commissure (arrow).

annulus (fig). The attachments of the other cusps were normal. Section of the cusps showed degenerative lesions of the elastin and collagen framework with focal calcification.

\section{Discussion}

The major disadvantage of tissue valves as human valve substitutes has been the unaccept. ably high rates of failure. The use of a flexible stent and glutaraldehyde preservation has reduced this significantly, and more encouraging results have been achieved with the porcine xenograft prosthesis. ${ }^{1-3}$ Indeed, the durability of the Hancock porcine xenograft appears to be comparable with that of currently available mechanical prostheses. However, several cases of valve failure from tissue degeneration have been reported with the Hancock prosthesis. ${ }^{2-6}$ Cusp perforation, leaflet calcification, and tears at the point of attachment of the commissure to the prosthetic struts have been the usual cause of valve failure. Histology invariably showed degenerative lesions of elastin and collagen framework with focal calcification. Findings were similar in our case whose glutaraldehyde fixed prosthesis had been inserted two and a half years earlier. Several hypotheses have been advanced to explain occasional failure of porcine aortic xenografts, but none seems entirely satisfactory. ${ }^{5-7}$ The degenerative lesions of the collagen and elastin framework have been interpreted as fatigue lesions and considered to be both progressive and inevitable in view of the nature of the bioprosthesis itself. ${ }^{8}$

Our findings seems to confirm this hypothesis, although a longer follow-up is required to assess whether the newly designed strut can improve the durability of the glutaraldehyde fixed aortic xenograft.

This case also illustrates the use of echocardiography in the management of these cases. Recording from the prosthesis indicated major abnormalities of the cusps. Digitisation of the left ventricular echogram demonstrated the presence of significant mitral regurgitation, at the same time excluding significant obstruction to inflow by the prosthesis or left ventricular disease, both of which might have explained the clinical picture on presentation.

\section{References}

1 Carpentier A, Deloche A, Relland J et al. Six year follow-up of glutaraldehyde-preserved heterografts. J Thorac Cardiovasc Surg 1974; 68:771-82.

2 McIntosh CL, Michaelis LL, Morrow AG, Itscoitz SC, Redwood DR, Epstein SE. Atrioventricular valve replacement with the Hancock porcine xenograft: a five years' clinical experience. Surgery 1975; 78:768-75.

3 Stinson EB, Griepp RB, Oyer PE, Shumway NE. Long-term experience with porcine aortic valve xenografts. J Thorac Cardiovasc Surg 1977; 73:54-63. 
4 Zuhdi H, Hawley W, Voehl V, Hancock W, Carey J, Greer A. Porcine aortic valves as replacement for human heart valves. Ann Thorac Surg 1974; 17:479-91.

5 Levitsky S. Discussion of Stinson et al. J Thorac Cardiovasc Surg 1977; 73:62.

6 Brown JW, Dunn JM, Spooner E, Kirsh MM. Late spontaneous disruption of a porcine xeno- graft mitral valve. Clinical, haemodynamic, $\stackrel{\overline{\bar{\rho}}}{\stackrel{5}{+}}$ echocardiographic and pathologic findings. $J$ Thorac Cardiovasc Surg 1978; 75:606-11.

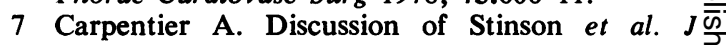
Thorac Cardiovasc Surg 1977; 73:61.

8 Broom ND. Fatigue-induced damage in glutaraldehyde-preserved heart valve tissue. J Thorac ${ }^{0}$ Cardiovasc Surg 1978; 76:202-11. 